LIVER FIBROSIS

\title{
SLC11A1 promoter gene polymorphisms and fibrosis progression in chronic hepatitis $C$
}

\author{
M Romero-Gómez, M A Montes-Cano, M A Otero-Fernández, B Torres, D Sánchez-Muñoz, \\ F Aguilar, N Barroso, L Gómez-Izquierdo, V M Castellano-Megias, A Núñez-Roldán, \\ J Aguilar-Reina, M F González-Escribano
}

Gut 2004;53:446-450. doi: 10.1136/gut.2003.028274

See end of article for authors' affiliations

Correspondence to: Dr M Romero-Gómez, Hepatology Unit, Hospital Universitario de Valme Ctra Cádiz s/n, 41014 Sevilla, Spain; mromerog@supercable.es

Accepted for publication 20 October 2003
Background and aims: The solute carrier family 11 member 1 (SLC11A1) gene (formerly Nrampl) encodes for the protein solute carrier family 11, member 1. It affects susceptibility and clinical outcome of autoimmune and infectious diseases. We investigated the possible role of the functional polymorphism located in the promoter region of SLC11A1 and tumour necrosis factor (TNF) genes in the progression of fibrosis in chronic hepatitis C.

Methods: A total of 242 Caucasian Spanish patients with biopsy proven chronic hepatitis C and 194 healthy control subjects were genotyped for SLC11Al and TNF promoter polymorphisms.

Results: No significant differences in the distribution of frequencies among patient and control groups were observed. The SCL11A1 homozygous $2 / 2$ genotype was rarely detected among patients showing advanced fibrosis $(2 / 82 ; 2.4 \%)$ but was highly represented in those with mild fibrosis $(29 / 160 ; 18.1 \%$; odds ratio (OR) 8.85 (95\% confidence interval (Cl) 1.9-55.2, $\left.p_{c}=0.002\right)$. In patients carrying allele 3 of SLC11A1, the presence of -238 TNF A/G was associated with advanced fibrosis (14/26 (53.8\%) v 68/216 (31.4\%); OR 2.53 (95\% Cl 1.03-6.23); $p=0.02$ ).

Conclusions: SLC11A1 gene promoter polymorphism could influence fibrosis progression in chronic hepatitis $C$ in that the homozygous genotype $2 / 2$ exerts a protective effect against cirrhosis development. Also, the combination of TNF $-238 \mathrm{~A} / \mathrm{G}$ and the presence of allele 3 is conducive to progression to precirrhotic or cirrhotic stages of the disease.
$\mathrm{T}$ he pathogenesis of hepatitis C virus (HCV) induced hepatic injury remains unclear but the major role played by the immune response mechanism in the control of viral replication and persistence in HCV induced liver disease has been well documented. ${ }^{1}$ Recently, several studies seeking candidate genes that may be involved in hepatitis $C$ have been conducted and the results indicate that genes coding for interleukin 10 (IL-10) or tumour growth factor $\beta$ (TGF- $\beta$ ) are particularly involved in fibrosis progression in chronic hepatitis C. ${ }^{23}$ Solute carrier family 11 member l (SLC11Al) protein is located in the late endosomal compartment of resting macrophages, and is recruited to the phagosome by phagocytosis. ${ }^{4}$ Functional studies with murine SLC11Al implicate its involvement in macrophage function, including upregulation of chemokine/cytokine genes such as tumour necrosis factor (TNF) and IL-1 $\beta$, and induction of nitric oxide synthase (iNOS). ${ }^{5}$ These functions play an important role in the immune response against HCV infection. Several mutations resulting in polymorphic mRNA expression have been identified in the SLC11Al gene. ${ }^{6}$ One of them, consisting of a variable number of tandem GT repeats, is located in the promoter region. Four alleles have been found in different populations: allele $1 \quad(\mathrm{GT})_{5} \mathrm{AC}(\mathrm{GT})_{11} \mathrm{G}$, allele 2 $(\mathrm{GT})_{5} \mathrm{AC}(\mathrm{GT})_{10} \mathrm{G}$, allele $3(\mathrm{GT})_{5} \mathrm{AC}(\mathrm{GT})_{9} \mathrm{G}$, and allele 4 $(\mathrm{GT})_{9} \mathrm{G}$ (the subscript numbers refer to the number of repeats at the polymorphic site). Functional differences relating to these alleles have been described. For example, in the absence of external stimuli, alleles 1, 2, and 4 are poor promoters whereas allele 3 drives high expression. ${ }^{7}$ One hypothesis has been that the SLC1lAl protein is an iron transporter that becomes saturated at high circulating iron concentrations $^{89}$ and hence, in circumstances of iron overload (which can occur in chronic hepatitis C infection), the result is fibrosis progression, a characteristic of the disease. $^{10}$

TNF has been shown to be involved in the immune response to HCV infection and fibrosis progression. ${ }^{11}$ Conflicting results have been reported with respect to the association of two biallelic polymorphisms located in the promoter region of the TNF gene (at positions $-238 \mathrm{TNF}$ A/G and $-308 \mathrm{TNF} A / G$ ) and cirrhosis development in chronic hepatitis C. ${ }^{312}{ }^{13}$ Indeed, higher serum concentrations of liver TNF have been shown to impair responses to antiviral therapy. ${ }^{14}$

The aim of this study was to analyse the possible involvement of known polymorphisms in the promoter regions of the SLCllAl and TNF genes in the progression of fibrosis in chronic hepatitis C infection.

\section{PATIENTS AND METHODS \\ Patients}

Spanish patients $(n=242)$ of Caucasian descent and with biopsy proven chronic hepatitis $\mathrm{C}$ infection were enrolled. The control group of subjects comprised 194 (105 men and 89 women) age and ethnicity matched volunteer bone marrow donors. Patients with alcohol consumption $>80$ g/day were excluded. No patient had been treated with interferon or with

\footnotetext{
Abbreviations: $\mathrm{SLC1} 1 \mathrm{Al}$, solute carrier family 11 member 1 ; HCV, hepatitis C virus; TGF, tumour growth factor; IL, interleukin; NOS, nitric oxide synthase; TNF, tumour necrosis factor; HIV, human immunodeficiency virus; $\mathrm{PCR}$, polymerase chain reaction; $\mathrm{OR}$, odds ratio; F, fibrosis; AST, aspartate aminotransferase; ALT, alanine aminotransferase; AP, alkaline phosphatase; GGT, gamma glutamyl transpeptidase
} 
Table 1 Epidemiological, biochemical, and histopathological features of the 242 patients with hepatitis $C$ virus included in the study

\begin{tabular}{lc}
\hline Age (y) & $44.9(11.7)$ \\
Infection duration (y) & $16.5(9.6)$ \\
Genotype & \\
Genotype 1 & 175 \\
Genotype non-1 & 37 \\
Unknown & 30 \\
Risk factors & \\
Drug user & 55 \\
Transfusion & 78 \\
Tattoos/piercing & 16 \\
Others/unknown & 93 \\
Sex & \\
Male & $170(70.2 \%)$ \\
Female & $72(29.7 \%)$ \\
Alcohol consumption $>30 \mathrm{~g} /$ day & \\
Yes & $65(26.8 \%)$ \\
No & $177(73.2 \%)$ \\
Fibrosis stage & \\
FO-F2 & $160(66.1 \%)$ \\
F3-F4 & $82(33.9 \%)$ \\
Portal inflammation & $2.48(1.02)$ \\
Lobular inflammation & $1.56(0.94)$ \\
Hepatocyte steatosis & \\
Present & $95(42.1 \%)$ \\
Absent & $129(57.8 \%)$ \\
Perl's staining & \\
Positive & $66(29.5 \%)$ \\
Negative & $158(70.5 \%)$ \\
Viral load (IU $\left.\times 10^{3} / \mathrm{ml}\right)$ & $1156(1390)$ \\
AST (U/I) & $70(53)$ \\
ALT (U/I) & $122(100)$ \\
AP (U/I) & $181(76)$ \\
GGT (U/l) & $48(43)$ \\
Ferritin (ng/ml) & $148(121)$ \\
Antinuclear antibody positive & $25(10.3 \%)$ \\
\hline
\end{tabular}

AST, aspartate aminotransferase; ALT, alanine aminotransferase; AP, alkaline phosphatase; GGT, gamma glutamyl transpeptidase.

other antiviral drugs prior to liver biopsy. The protocol was approved by the ethics committees of the Hospital Universitario de Valme and Hospital Universitario Virgen del Rocio (Sevilla). All biopsies from patients and genetic analyses on patients and volunteers were performed with fully informed written consent and with anonymity of the data being guaranteed.

\section{Laboratory analyses}

All patients had raised alanine aminotransferase (ALT) concentrations and positive anti-HCV and HCV RNA in serum, but were hepatitis B surface antigen and anti-human immunodeficiency virus (HIV) negative. Additionally, serum HCV RNA levels were quantified using Amplicor-HCVMonitor (Perkin-Elmer, Norwalk, Connecticut, USA) and HCV genotypes were determined using Inno-lipa HCV II (Innogenetics, Zwijnaarden, Belgium). All commercial kits were used according to the manufacturer's instructions.

\section{Liver biopsies}

Percutaneous liver biopsies were performed under ultrasonographic guidance. Grading and staging assignments were according to the system of Scheuer. ${ }^{15}$ These were: necroinflammatory activity (grade): (a) portal inflammation and interface hepatitis ranging in grade from absent (P0) to severe and widespread interface hepatitis (P4); (b) lobular activity ranging from none (LO) to bridging confluent necrosis (L4); fibrosis (stage): ranging from no fibrosis (F0) to cirrhosis (F4). Hepatocyte steatosis and iron staining were also evaluated. Grading of hepatic iron deposition was performed on paraffin embedded sections of liver biopsy specimens stained with Perl's Prussian blue. Liver biopsy was
Table 2 Allele and genotype frequencies of the $\mathrm{SLC1} 1 \mathrm{~A} 1$ polymorphisms in chronic hepatitis $\mathrm{C}(\mathrm{HCV})$ patients and in a healthy control group of subjects

\begin{tabular}{lcc}
\hline SLC11A1 & $\begin{array}{c}\text { HCV patients } \\
\text { (n=242) }\end{array}$ & $\begin{array}{c}\text { Healthy controls } \\
\text { ( } \mathbf{n}=194)\end{array}$ \\
\hline Allele frequencies & & \\
(48 bp) 1 & 0.006 & 0.008 \\
(46 bp) 2 & 0.311 & 0.278 \\
(44 bp) 3 & 0.671 & 0.714 \\
(34 bp) 4 & 0.000 & 0.000 \\
Genotype frequencies & & \\
$1 / 1$ & $0(0 \%)$ & $0(0 \%)$ \\
$1 / 2$ & $3(1.2 \%)$ & $1(1 \%)$ \\
$1 / 3$ & $5(2.1 \%)$ & $2(1 \%)$ \\
$1 / 4$ & $0(0 \%)$ & $0(0 \%)$ \\
$2 / 2$ & $28(11.6 \%)$ & $15(8 \%)$ \\
$2 / 3$ & $92(38 \%)$ & $76(39 \%)$ \\
$2 / 4$ & $0(0 \%)$ & $0(0 \%)$ \\
$3 / 3$ & $114(47.1 \%)$ & $100(52 \%)$ \\
$3 / 4$ & $0(0 \%)$ & $0(0 \%)$ \\
$4 / 4$ & $0(0 \%)$ & $0(0 \%)$ \\
\hline No statistically significant differences were observed in any of the \\
variables.
\end{tabular}

not available from 18 patients who had biochemical, endoscopic, and ultrasound features of liver cirrhosis. These patients were classified as F4.

\section{Genotyping}

Genetic studies were performed on genomic DNA isolated from peripheral blood samples from patients and control subjects using standard extraction methods. ${ }^{16}$ In the case of SLC11Al microsatellite promoter region polymorphism, genotyping was performed using the polymerase chain reaction (PCR) carried out in a Perkin-Elmer 9600 Thermal Cycler (Perkin-Elmer, Foster City, California, USA) with reaction mixtures consisting of $1 \mu \mathrm{l}$ of genomic DNA, 2.5 pmol of each primer, $200 \mu \mathrm{M}$ of each dNTP and $0.2 \mathrm{U}$ Taq DNA polymerase in a final volume of $10 \mu \mathrm{l}$. The polymorphic region was amplified using sense (5'ACTCGCATTAGGCCAACGAG-3') 5'-end labelled with HEX (Perkin-Elmer) and antisense (5'TGTGCCCCACAACACATCTG-3') primers. The thermal cycle profile was: initial denaturation at $95^{\circ} \mathrm{C}$ over five minutes followed by 30 cycles of $94^{\circ} \mathrm{C}$ for one minute, $55^{\circ} \mathrm{C}$ for one minute, and $72^{\circ} \mathrm{C}$ for one minute, and a final extension at $72{ }^{\circ} \mathrm{C}$ for seven minutes. PCR amplified fragments were separated by electrophoresis in a capillary system (ABI PRISM 310; Perkin-Elmer). The lengths of the fragments were analysed using Genescan 672 software (Perkin-Elmer). Fragment size markers (500 TAMRA; Perkin-Elmer) were used as reference.

Table 3 Relationship between the tumour necrosis factor (TNF) and solute carrier family 11 member 1 (SLC11A1) polymorphisms and liver fibrosis

\begin{tabular}{|c|c|c|c|}
\hline \multirow[b]{2}{*}{ Polymorphisms } & \multicolumn{2}{|c|}{ Fibrosis } & \multirow[b]{2}{*}{ p Value } \\
\hline & F0-F2 & F3-F4 & \\
\hline TNF $-238 \mathrm{~A} / \mathrm{G}$ & 17 & 14 & \\
\hline TNF $-238 \mathrm{G} / \mathrm{G}$ & 143 & 68 & 0.303 \\
\hline TNF $-308 \mathrm{~A} / \mathrm{G}$ & 45 & 20 & \\
\hline $\mathrm{TNF}-308 \mathrm{G} / \mathrm{G}$ & 115 & 62 & 0.223 \\
\hline Genotype 2/2 & $29+$ & 2 & \\
\hline Genotype $3 / 3$ or 3 /others & 131 & 80 & $0.0005^{*}$ \\
\hline
\end{tabular}

*Odds ratio 8.85 (95\% confidence interval 1.9-55.2); $p_{c}=0.002$. †Three patients bearing genotype $2 / 1$ showed FO-F2 fibrosis. 
Table 4 Biochemical, histological, and virological features divided with respect to the solute carrier family 11 member 1 (SLC11A1) polymorphisms

\begin{tabular}{|c|c|c|c|}
\hline & \multicolumn{2}{|c|}{ SLC11Al genotype } & \multirow[b]{2}{*}{$\mathrm{p}$ Value } \\
\hline & $\overline{2 / 2}$ & $3 / 3$ or $3 /$ other & \\
\hline \multirow{2}{*}{\multicolumn{4}{|c|}{ Alcohol }} \\
\hline & & & \\
\hline Yes & 7 & 58 & NS \\
\hline No & 21 & 153 & \\
\hline Body mass index $\left(\mathrm{kg} / \mathrm{m}^{2}\right)$ & $26.1(5.3)$ & $27.2(5.7)$ & NS \\
\hline AST (U/I) & $74(53)$ & $69(53)$ & NS \\
\hline ALT (U/I) & $110(86)$ & $124(102)$ & NS \\
\hline AP (U/I) & $175(56)$ & $182(79)$ & NS \\
\hline GGT (U/I) & $57(41)$ & $46(43)$ & NS \\
\hline Ferritin $(\mathrm{ng} / \mathrm{ml})$ & 150 (125) & $148(145)$ & NS \\
\hline HCV viral load (Th IU/ml) & $336(421)$ & 1290 (1345) & 0.012 \\
\hline Portal inflammation & $1.9(1.1)$ & $2.5(1.0)$ & 0.031 \\
\hline Lobular inflammation & $1.8(0.8)$ & $1.8(0.9)$ & NS \\
\hline Perl's stain (+) & 7 & 59 & NS \\
\hline Perl's stain (-) & 21 & 134 & \\
\hline Steatosis (yes) & 8 & 87 & NS \\
\hline Steatosis (no) & 20 & 106 & \\
\hline
\end{tabular}

$\mathrm{HCV}$, hepatitis C virus; $A S T$, aspartate aminotransferase; $A L T$, alanine aminotransferase; $A P$, alkaline phosphatase; GGT, gamma glutamyl transpeptidase.

TNF -238 and -308 promoter genotyping was performed employing a PCR-amplification refractory mutation system carried out in a Perkin-Elmer 9600 Thermal Cycler with reaction mixtures consisting of $1 \mu \mathrm{l}$ of genomic DNA, 2.5 pmol of each primer, $200 \mu \mathrm{M}$ of each dNTP, and $0.2 \mathrm{U}$ Taq DNA polymerase in a final volume of $10 \mu \mathrm{l}$. Primers were designed according to the published human TNF sequence obtained from the GeneBank (accession No 1353717) ${ }^{17}$ (R2). Forward primers were: 5' ATAGGTTTTGAGGGGCATGG 3' and 5' ATAGGTTtTGAGGGGCATGA $3^{\prime}$ for the -308 mutation, and 5' GAAGACCTCTCTCAGATCA 3' and GAAGACCTCTCTAGAATCG for the -238 mutation. Reverse primer was 5' GGTTTCTTCTCCATCACTGG 3' in both cases. For each sample, two independent PCR reactions were carried out for each dimorphism. The following thermal profile applied to the -308 position: initial denaturing at $95^{\circ} \mathrm{C}$ over five minutes, followed by 10 cycles of $94^{\circ} \mathrm{C}$ for 10 seconds and $62^{\circ} \mathrm{C}$ for 20 seconds, and 20 cycles of $94^{\circ} \mathrm{C}$ for 10 seconds, $52^{\circ} \mathrm{C}$ for 30 seconds, and $72^{\circ} \mathrm{C}$ for 30 seconds. In the case of the -238 mutation, the thermal profile was: initial denaturing at $95^{\circ} \mathrm{C}$ over five minutes, followed by 30 cycles of $94^{\circ} \mathrm{C}$ for 30 seconds, $50^{\circ} \mathrm{C}$ for 30 seconds, and $72^{\circ} \mathrm{C}$ for 30 seconds. Amplified fragments were separated on 2\% agarose gel stained with ethidium bromide. Samples showing the expected fragments (171 bp for -308 and $101 \mathrm{bp}$ for -238 ) in a single tube were assigned as the homozygous AA or GG genotype while samples showing amplification in both tubes were assigned the heterozygous AG genotype.

\section{Statistical analysis}

Allelic and genotype frequencies were obtained by direct counting. Data are presented as mean (SD) in the text and tables. Data were compared with $\mathrm{n} \times 2$ or $2 \times 2$ contingency tables using the Statcalc program (Epi Info version 6.0; Center for Disease Control and Prevention, Atlanta, Georgia, USA). The $\chi^{2}$ test was used in statistical comparisons. Fisher's exact test was used when one expected value was less than 5 and $p$ values were corrected $\left(p_{c}\right)$ by multiplying by the number of comparisons. Odds ratios (OR) with $95 \%$ confidence intervals (95\% CI) were calculated using the same software. Backward logistic regression was used to analyse the influence of alcohol, steatosis, sex, age, duration of disease, body mass index, and gene polymorphism in relation to progression of liver fibrosis.

Table 5 Biochemical, histological, and virological features divided with respect to tumour necrosis factor (TNF) polymorphisms

\begin{tabular}{|c|c|c|c|c|c|c|}
\hline & \multicolumn{3}{|l|}{ TNF } & \multicolumn{3}{|l|}{ TNF } \\
\hline & -238 A/G & $-238 \mathrm{G} / \mathrm{G}$ & p Value & $-308 \mathrm{~A} / \mathrm{G}$ & $-308 \mathrm{G} / \mathrm{G}$ & p Value \\
\hline $\begin{array}{l}\text { Infection duration (y) } \\
\text { Alcohol }\end{array}$ & 19 (12) & $16(9)$ & NS & $17(10)$ & $15(9)$ & NS \\
\hline Yes & 8 & 57 & & 21 & 44 & NS \\
\hline No & 23 & 154 & NS & 44 & 133 & \\
\hline Body mass index $\left(\mathrm{kg} / \mathrm{m}^{2}\right)$ & $27.1(5.4)$ & $26.4(5.4)$ & NS & $25.4(5.7)$ & $27.6(5.8)$ & NS \\
\hline AST (U/I) & $69(63)$ & $70(51)$ & 0.24 & $74(49)$ & $68(54)$ & NS \\
\hline ALT (U/I) & $123(130)$ & $122(96)$ & NS & $138(93)$ & $119(103)$ & NS \\
\hline $\operatorname{AP}(U / I)$ & $188(68)$ & $181(78)$ & NS & $183(68)$ & $181(80)$ & NS \\
\hline GGT (U/l) & $60(47)$ & $47(42)$ & NS & 47 (44) & $49(42)$ & NS \\
\hline Ferritin $(\mathrm{ng} / \mathrm{ml})$ & 214 (144) & 140 (139) & NS & 150 (167) & 149 (133) & NS \\
\hline HCV Viral load (Th IU/ml) & $1026(1048)$ & 1170 (1425) & NS & 1157 (1432) & 1115 (1332) & NS \\
\hline Portal inflammation & $2.7(0.9)$ & $2.4(1.1)$ & NS & $2.5(1.03)$ & $2.5(1.0)$ & NS \\
\hline Lobular inflammation & $1.93(0.9)$ & $1.8(0.9)$ & NS & $1.85(1.02)$ & $1.8(0.9)$ & NS \\
\hline Perl's stain (+) & 6 & 60 & NS & 18 & 48 & NS \\
\hline Perl's stain (-) & 21 & 137 & & 42 & 116 & \\
\hline Steatosis (yes) & 15 & 80 & NS & 24 & 71 & NS \\
\hline Steatosis (no) & 12 & 117 & & 36 & 93 & \\
\hline
\end{tabular}

$\mathrm{HCV}$, hepatitis C virus; AST, aspartate aminotransferase; ALT, alanine aminotransferase; AP, alkaline phosphatase; GGT, gamma glutamyl transpeptidase. 
Table 6 Distribution of advanced or early fibrosis, divided with respect to the presence of allele 3 of the solute carrier family 11 member 1 (SLC11A1) and tumour necrosis factor (TNF) polymorphisms

\begin{tabular}{lccc}
\hline & \multicolumn{2}{c}{ Fibrosis } & \\
\cline { 2 - 3 } SLC1 1A1 allele/-238 TNF polymorphisms & F0-F2 & F3-F4 & \% Fibrosis \\
\hline Non-allele 3 TNF -238 A/G & 6 & 0 & 0 \\
Non-allele 3 TNF -238 G/G & 23 & 2 & 8 \\
Allele 3 TNF -238 A/G & 12 & 14 & 54 \\
Allele 3 TNF -238 G/G & 119 & 66 & 36
\end{tabular}

Patients carrying allele 3 and TNF $-238 \mathrm{~A} / \mathrm{G}$ showed a higher proportion of advanced fibrosis than patients with allele 3 and wild-type TNF.

Pearson $\chi^{2}: 14.03 ; p=0.002 ; p_{c}=0.016$.

\section{RESULTS}

\section{Population sample}

Epidemiological, biochemical, and histological features of the population studied are summarised in table 1 . No significant differences were noted between patients and control subjects with respect to age or sex distributions. The distribution of SLC11Al genotypes in patients and control subjects are presented in table 2. The frequencies of the genotypes were found to be not significantly different from those predicted from the Hardy-Weinberg equilibrium in patients as well as in the control population. No significant differences were observed in the distributions of allele and genotype frequencies of SLCllAl promoter region polymorphisms between $\mathrm{HCV}$ infected patients and healthy control subjects.

\section{Genetic factors in fibrosis progression}

After stratification with respect to fibrosis status in group F0F2 and group F3-F4, no significant differences in the distribution of the -238 TNFA and -308 TNFA genotypes were observed between these patient groups (table 3). However, there was a significant deviation between the patient groups $\left(\chi^{2}\right.$ test, $\left.p=0.0005\right)$ with respect to the distribution of the most frequent SLC11Al genotypes. This deviation was caused by a significantly different distribution of the 2/2 genotype among patients showing advanced fibrosis $(2.4 \%)$ and patient displaying fibrosis stages $\mathrm{F} 0-\mathrm{F} 2$ (18.1\%) (OR 8.85 (95\% CI 1.9-55.2); $\left.\mathrm{p}_{\mathrm{c}}=0.002\right)$.

\section{Relationship between SLC11A1 genotypes and inflammatory activity and viraemia}

Patients carrying the $2 / 2$ genotype showed lower HCV RNA levels (336 (421) v 1290 (1345) $\mathrm{IU} \times 10^{3} / \mathrm{ml} ; \mathrm{p}=0.012$ ) and lower degree of portal inflammation (1.9 (1.1) $v 2.6$ $(1.0) ; \mathrm{p}=0.031$ ) than the other genotypes (table 4$)$. No differences among TNFA genotypes were observed with respect to biochemical, histology, or clinical features (table 5).

\section{Interaction between -238 TNF and SLC 11 A 1} genotype $3 / 3$ in the development of advanced fibrosis A significant deviation in the distribution of patients with respect to their SLC11Al/-238 TNF alleles between both patient groups was observed $\left(\chi^{2}\right.$ test, $\left.p=0.002\right)$. This deviation was caused by a difference in the distribution of individuals carrying the allele 3 of SLCIIAl and the $\mathrm{A} / \mathrm{G}-238 \mathrm{TNF}$ among patients showing advanced fibrosis $(14 / 26(53.8 \%) \vee 68 / 216(31.4 \%)$ of the other genotypes, $\mathrm{p}=0.039$; OR 2.53 (95\% CI 1.03-6.23)) (table 6).

\section{Multivariate analysis (backward logistic regression)}

To analyse the influence of age, sex, duration of infection (years), alcohol consumption, presence of steatosis, body mass index, iron staining, portal inflammation, SCLllAl genotype 2/2, and haplotypes SCL11Al-TNF 238 on fibrosis stage in the liver samples, a backward logistic regression analysis was performed. The results indicated that alcohol (OR 4.59 (95\% CI 1.85-11.36); $\mathrm{p}=0.001)$, age (OR $0.92(95 \%$ CI $0.89-0.96) ; \mathrm{p}=0.0001$ ), $\operatorname{sex}(\mathrm{OR} 0.41$ (95\% CI $0.18-0.95)$; $\mathrm{p}=0.03$ ), and genotype $2 / 2$ of SLC1 1Al (OR 25 (95\% CI $2.41-$ 272.9); $\mathrm{p}=0.007$ ) were independent variables associated with fibrosis stage. Perl's staining for iron, portal inflammation, TNF polymorphism, and steatosis did not enter into the equation.

\section{DISCUSSION}

The $2 / 2$ genotype of the promoter region of the SLC11Al gene (that is, homozygosity for allele $\left.2(\mathrm{GT})_{5} \mathrm{AC}(\mathrm{GT})_{10} \mathrm{G}\right)$ has been found, in the current study, to be associated with lower HCV replication in serum and mild portal inflammation, together with a lack of advanced fibrosis. SLCllAl is located at 2q35 and mutations giving rise to polymorphisms in the promoter region have been related to susceptibility to rheumatoid arthritis, ${ }^{16}$ tuberculosis, ${ }^{18}$ and HIV infection. ${ }^{19}$ A role for genetic factors in the regulation of serum HCV levels has been proposed which implicates mainly the HLA class II haplotypes. ${ }^{20}$ However, explanations for the underlying mechanism remain elusive. Several aspects of the functional activity of SLC11Al could explain our results, at least in part. Firstly, SLC11Al could regulate secretion of several cytokines such as TNF or TGF- $\beta^{21}$ which are involved in the activation of hepatic stellate cells and progression of fibrosis in chronic hepatitis C. ${ }^{22}$ Secondly, one of the mechanism proposed to explain the higher susceptibility to tuberculosis of individuals bearing the SLC11Al 2/2 genotype has been upregulation of IL-10 production by monocytes. ${ }^{23}$ Indeed, IL-10 shows an important anti-inflammatory and antifibrogenic activity and this could be responsible for the low rate of cirrhosis in HVC patients carrying this SCLllAl genotype. ${ }^{24}$ Thirdly, the SLCllAl gene could modulate Kupffer cell activation with higher TNF production in individuals carrying the 3 allele. ${ }^{25}$ Fourthly, SLC11Al has been associated with increased nitric oxide production and enhanced iNOS in hepatocytes and macrophages. ${ }^{26}$ Nitric oxide has been implicated in the pathogenesis of chronic hepatitis $\mathrm{C}$, mainly via peroxinitrite; a potential oxidant that is produced by the reduction of superoxide anion with nitric oxide. ${ }^{27}$ Recently, cooperation between TNF and SLCllAl genes was shown to result in raised nitric oxide production following cytokine stimulation. ${ }^{28}$ This mechanism could explain the advanced fibrosis found in patients carrying the 3/3 SLC11Al genotype and the A/G -238 TNF mutation. Fifthly, it is possible that alleles of some other gene in linkage disequilibrium with the ones currently studied is the underlying cause of a modified immune response that induces cirrhosis progression in the presence of allele 3 of the SLC1IAl gene. ${ }^{29}$ Indeed, IL- 8 receptor gene is in an adjacent location to the SLCllAl gene 
and this chemokine has been associated with viral persistence and resistance to interferon therapy. ${ }^{30}$

Although the association between genotype 2/2 and lack of fibrosis progression achieved statistical significance and the SLC11Al gene has potential functional importance in fibrosis progression, these results need to be confirmed in further studies. Although the number of individuals in each group was too low to make definite conclusion regarding outcome, the mechanisms proposed (above) could explain, at least in part, why patients carrying the $2 / 2$ genotype have less severe fibrosis. Allele 3 of SLC11Al, together with the A/G -238 TNF, was associated with precirrhotic or cirrhotic stages in patients with chronic hepatitis $\mathrm{C}$. Nevertheless, multivariate analysis indicated that genotype $2 / 2$ of SLC1 1Al was strongly associated with mild fibrosis and excluded interactions between SLC11Al and TNF $-238 \mathrm{~A} / \mathrm{G}$ from being independent variables. An interaction between several polymorphisms of genes causing progressive fibrosis in chronic hepatitis $\mathrm{C}$ had been reported. Patients carrying the TGF- $\beta 125 \mathrm{Arg} / \mathrm{Arg}$ and the AT- 6 A/A combined had higher fibrosis scores than patients bearing either one alone or carrying the wild types. ${ }^{3}$ It is important however to remember that these genes account for only a small proportion of the total genetic background implicated in the progression of fibrosis in chronic hepatitis C. A better understanding of the molecular bases of this observation could have major implications for the development of novel therapies and vaccines.

In summary, our data suggest that the SLC1lAl gene may be implicated in the regulation of fibrosis; the genotype $2 / 2$ exerting a protective effect against fibrosis progression. Also, interaction between allele 3 of SLC11Al and the $-238 \mathrm{~A} / \mathrm{G}$ mutation in the promoter region of the TNF gene appears to induce advanced fibrosis progression in patients with chronic hepatitis C.

\section{ACKNOWLEDGEMENTS}

This study was supported in part by grants from Fondo de Investigaciones Sanitarias (FIS 00/0566) and Plan Andaluz de Investigación (PAI, grupos CTS-913, CTS-197 and CTS-102) and a grant (16/01) from Junta de Andalucia and (G03/155) from the Spanish Ministry of Health.

\section{Authors' affiliations}

\section{Romero-Gómez, M A Otero-Fernández, D Sánchez-Muñoz,} Hepatology Unit, Hospital Universitario de Valme, Sevilla, Spain M A Montes-Cano, B Torres, F Aguilar, A Núñez-Roldán, M F GonzálezEscribano, Immunology Department, Hospital Universitario Virgen del Rocio, Sevilla, Spain

N Barroso, J Aguilar-Reina, Hepatology Section (Digestive Service), Hospital Universitario Virgen del Rocio, Sevilla, Spain

L Gómez-Izquierdo, Pathology Unit, Hospital Universitario Virgen del Rocio, Sevilla, Spain

V M Castellano-Megias, Pathology Unit, Hospital Universitario de Valme, Sevilla, Spain

\section{REFERENCES}

1 Chang KM. Immunopathogenesis of hepatitis C virus infection. Clin Liver Dis 2003;7:89-105.

2 Vidigal PG, Germer JJ, Zein NN. Polymorphisms in the interleukin-10, tumor necrosis factor-alpha, and transforming growth factor-betal genes in chronic hepatitis $C$ patients treated with interferon and ribavirin. J Hepatol 2002;36:271-7.

3 Powell EE, Edwards-Smith CJ, Hay JL, et al. Host genetic factors influence disease progression in chronic hepatitis C. Hepatology 2000;31:828-33.

4 Gruenheid S, Pinner E, Desjardins M, et al. Natural resistance to infection with intracellular pathogens: the Nrampl protein is recruited to the membrane of the phagosome. J Exp Med 1997; 185:717-30.

5 Blackwell JM, Searle S, Mohamed H, et al. Divalent cation transport and susceptibility to infectious and autoimmune disease: continuation of the lty/ Lsh/Bcg/Nrampl/Slcl lal gene story. Immunol Lett 2003;85:197-203.

6 Liu J, Fujiwara TM, Buu NT, et al. Identification of polymorphisms and sequence variants in the human homologue of the mouse natural resistanceassociated macrophage protein gene. Am J Hum Genet 1995;56:845-53.

7 Bellamy R. Susceptibility to mycobacterial infections: the importance of host genetics. Genes Immun 2003;4:4-11.

8 Levy JE, Montross LK, Andrews NC. Genes that modify the hemochromatosis phenotype in mice. J Clin Invest 2000; 105:1209-16.

9 Barton CH, Biggs TE, Baker ST, et al. Nrampl: a link between intracellular iron transport and innate resistance to intracellular pathogens. J Leukoc Biol 1999;66:757-62

10 Tung BY, Emond MJ, Bronner MP, et al. Hepatitis C, iron status, and disease severity: relationship with HFE mutations. Gastroenterology 2003; 124:318-26.

11 Crespo J, Rivero M, Fabrega E, et al. Plasma leptin and TNF-alpha levels in chronic hepatitis $C$ patients and their relationship to hepatic fibrosis. Dig Dis Sci 2002;47:1604-10.

12 Romero-Gómez M, González-Escribano MF, Torres B, et al. HLA Class I B44 is associated with sustained response to interferon+ribavirin therapy in patients with chronic hepatitis C. Am J Gastroenterol 2003:98:1621-6.

13 Yee L, Tang J, Herrera J, et al. Tumor necrosis factor gene polymorphisms in patients with cirrhosis from chronic hepatitis $C$ virus infection. Genes Immun 2000; 1:386-90.

14 Kimball P, Elswick RK, Shiffman M. Ethnicity and cytokine production gauge response of patients with hepatitis $C$ to interferon-alpha therapy. J Med Virol 2001;65:510-16.

15 Schever PJ. Classification of chronic viral hepatitis: a need for reassessment. J Hepatol 1991;13:372-3.

16 Rodriguez MR, Gonzalez-Escribano MF, Aguilar F, et al. Association of NRAMP1 promoter gene polymorphism with the susceptibility and radiological severity of rheumatoid arthritis. Tissue Antigens 2002;59:31 1-5.

17 http:// www.ncbi.nlm.nih.gov/.

18 Searle S, Blackwell JM. Evidence for a functional repeat polymorphism in the promoter of the human NRAMP1 gene that correlates with autoinmune versus infetious disease susceptibility. J Med Genet 1999;36:295-9.

19 Marquet S, Sanchez FO, Arias M, et al. Variants of the human NRAMP1 gene and altered human immunodeficiency virus infection susceptibility. $J$ Infect Dis 1999; 180:1521-5

20 Fanning $\mathrm{U}$, Levis J, Kenny-Walsh E, et al. HLA class II genes determine the natural variance of hepatitis C viral load. Hepatology 2001;33:224-30.

21 Gershwin ME. The natural history of primary biliary cirrhosis: of genes and cooperation. J Hepatol 2001;35:412-5.

22 Schuppan D, Krebs A, Baver $M$, et al. Hepatitis $C$ and liver fibrosis. Cell Death Differ 2003;10(suppl 1):S59-67.

23 Awomoyi AA, Marchant A, Howson JMM, et al. Interleukin-10, polymorphism in SLC11A1 (formerly Nramp1), and susceptibility to tuberculosis. J Infect Dis 2002;186:1808-14.

24 Napoli J, Bishop GA, McGuinness PH, et al. Progressive liver injury in chronic hepatitis $C$ infection correlates with increased intrahepatic expression of Th1associated cytokines. Hepatology 1996;24:759-65.

25 Wyllie S, Seu P, Gao FQ, et al. Disruption of the Nrampl (also known as Slcl lal) gene in Kupffer cells attenuates early-phase, warm ischemiareperfusion injury in the mouse liver. J Leukoc Biol 2002;72:885-97.

26 Nathan C. Natural resistance and nitric oxide. Cell 1995;82:873-6.

27 Kandemir O, Polat A, Kaya A. Inducible nitric oxide synthase expresión in chronic viral hepatitis and its relation with histological severity of disease. $J$ Viral Hepat 2002;96:419-23.

28 Ables GP, Takamatsu D, Noma H, et al. The roles of Nrampl and TNFa genes in nitric oxide production and their effect on the growth of Salmonella typhimurinum in macrophages from Nrampl congenic and tumor necrosis factor-alpha -/- mice. J Interferon Cytokine Res 2001;21:53-62.

29 Yip SP, Leung KH, Lin CK. Extent and distribution of linkage disequilibrium around the SLC11A1 locus. Genes Immun 2003;4:212-21.

30 Polyak SJ, Khabar KS, Rezeiq M, et al. Elevated levels of interleukin-8 in serum are associated with hepatitis $C$ virus infection and resistance to interferon therapy. J Virol 2001;75:6209-11. 